\title{
SCHOOL NOTIFICATION OF INFECTIOUS DISEASE.
}

\author{
By JOHN J. BOYD, M.B., C.M., D.P.H. \\ Medical Officer of Health for South Shields.
}

In bringing this subject forward for discussion to-day, my motive is to seek for information rather than to impart it. The subject of the relations between medical officers of health and elementary schools has been lately rather prominently brought before the Society, especially by Dr. Richards in his interesting paper and in the discussion which followed it.

Limitations.--In that paper and diseussion the whole question of the control of schools from a public health point of view was under consideration, the discussion closing with the adoption of a series of resolutions to be submitted to the Board of Education and the Local Government Board. I shall, however, in the few remarks I am about to make, confine myself within much narrower limits- to the consideration, namely, of the prevention or control of infectious or zymotic disease by utilizing the school as a

Notification Agency and an Inspection Ground.-I therefore limit myself to two out of the eight resolutions passed at the meeting I have just referred to-viz., Nos. 2 and 8.

As regards No. 2, the power of entry to all public elementary schools can, I take it, be without difficulty given to the medical officer of health by resolution of the Town and County Council ; the examination of scholars might also, I suppose, be authorized by the same authority, as it is at present by school managers, and could not be objected to by parents as long as it consisted of a mere inspection of exposed parts-hands, face, tongue, throat. The taking of swabs from the throat or any more detailed examination would, I think, require to be done at the child's house, when the consent of the parent could be obtained.

For practical purposes, then, I consider that it is not necessary to go beyond the Town Council for the powers asked for in this resolution.

The same remark would seem to apply to resolution 8. For many years both resolutions have been practically acted on in South Shields. The right of entry, and the examination of children by the medical officer of health, have never been objected to either by School Board or by voluntary schools, with, I think, one exception. I quite understand that the arrangement has been a voluntary one, which might have been put a stop to at any time by the Board or the school managers; but owing to the advantage accruing from it. 
being so evidently mutual, this termination was highly unlikely. Now, however, the new Education Act, having placed the Town Council as the supreme authority over all the elementary schools, I presume that they can grant the necessary powers to their medical officer of health. Whether it is advisable that the medical officer of health should be appointed medical officer to the School Board or Education Committee is a different question.

Notification of Infectious Disease.-I pass on now to the first of my two points-viz., how far, and in what manner, the schools may best be used as a notification agency. Our present methods in South Shields, which, no doubt, are very similar to those in use in other boroughs, are that, in addition to the notification by medical practitioners of the diseases mentioned in the Notification Act, we receive notification from the headmasters and mistresses of the various schools of cases of measles, chicken-pox, and whooping-cough. On receipt of the school notification, a visit is made by the sanitary inspector, who leaves printed instructions regarding the disease from which the child is suffering, and inquires whether any doctor is in attendance. Should there be no medical man in attendance, a visit is then made-by the medical officer of health to confirm the diagnosis of the parent or otherwise. On the other hand, information is sent by the Health Office to the schools with regard to all cases of disease notified under the Notification Act where children are attending from the infected house.

Slowness of Notification. - The present system of notification, whether by schools or by medical men, cannot be regarded as altogether satisfactory. The information is not received by the medical officer of health sufficiently early in the course of the illness for him to make the best use of it in limiting the spread of disease.

As far as cases notified by medical men are concerned, this arises from the fact that they are not called in until two or three days after the commencement of the illness. In the case of the schools, it largely arises from the roundabout route by which the information has to travel on its road to the medical officer of health. As an illustration of this slowness of notification, I may mention that out of a total of 549 secondary scarlet fever cases which were notified in Shields during the years 1901 and 1902, no less than 212 were notified at the same time as the primary case, being 38 per cent. During the last four months, of 108 scarlet fever cases: notified, 3 notifications were received on the first day, 11 on the second, 34 on the third, 25 on the fourth, 12 on the fifth, 5 on the sixth, 4 on the seventh, and 14 later. Now, of all infectious diseases, scarlet fever is the disease in which early notification is easiest, on account of the early presence of the characteristic symptoms. It is 
also a disease which is most infectious in its earliest stages. In the case of the other diseases mentioned, measles and whooping-cough, the notification can never, I fear, be so prompt, and therefore so useful, as in the case of scarlet fever. In measles we have three days of infectivity before the rash appears, and in whooping-cough about a fortnight.

Notification of these latter diseases by the family medical attendant, seeing how comparatively slow and unsatisfactory is such notification of even scarlet fever, is, I consider, of no value. In the different towns where it has been tried it has proved practically useless.

It is by a further development of school notification, and an improvement in the method thereof, that I think we shall obtain that earlier information which is so desirable.

The diseases under consideration are practically confined to children, and an enormous proportion of these children are attending the public elementary schools. The proportion of families represented in these schools, although with certain members either too young or too old to attend, is even greater.

It may be taken as a universal rule that school attendance on the part of the child attacked by infectious disease ceases at a measureably earlier period than his examination by a medical man. In the case of searlet fever, I find that it is quite an exception for an affected child to go on attending school in the early stage of the disease. The initial vomiting may fairly often happen in school, but the child is at once withdrawn. On the other hand, whilst keeping the sick child away from school, and frequently, also, the other members of the family, it is the commonest thing for the parents to delay sending for medical advice for some days.

Again, I find that notification of infectious disease to the Health Office by parents, although obligatory under the Notification Act, is practically never done and cannot be enforced. Even where notices requiring such notification are prominently posted over the town, as is at present the case in South Shields with reference to chicken-pox, very few cases indeed are so reported. On the other hand, these cases are reported to the school authorities, and by them to the Health Office.

Effects of Delay in Notification.-The evil effects, in the way of spread of the disease, of this slowness of notification are very apparent. During these two or more days not only are the family in the affected house freely exposed to infection, but by the children playing in the back lanes and round about the doors the infection is passing to the surrounding houses. 
Now, I consider that a method of school notification might be devised which would give us the important information we require perhaps forty-eight hours earlier than we get it at present.

Attendance Officer.-In the school attendance officer we have an official whose duty it is to inquire into the cause of the absence of school children. In South Shields whenever a child imisses two attendances his name is handed to the attendance officer, who visits the house within thirty-six hours of the non-appearance of the child at school. At present any information which he may obtain regarding disease is sent by him to the headmaster of the affected school, who receives it thirty-six hours after the name was sent in. Another twenty-four hours probably elapses before it reaches the medical officer of health. Sometimes the delay is much greater, the school authorities only handing names of absentees to the attendance officer twice a week.

To avoid this delay I consider that every attendance officer should be ex-officio a sanitary inspector, with certain limited and defined duties as such. On visiting the house of an absentee, it should be his duty to ascertain as accurately as possible the nature of the illness where such is assigned as a reason for absence.

He should also inquire if there is a doctor attending, and obtain the name of the doctor. Where the disease is of an infectious nature, he should give the parent a printed form of instructions regarding the particular disease in question (a supply of these he would obtain at the Health Office, and carry with him on his rounds). He would be required to forthwith inform the medical officer of health, either by calling at the Health Office on the day of his visit to the case, and leaving a properly filled up form with the necessary particulars, or in cases where the disease was one for which hospital accommodation was available and necessary by telephoning. Where no doctor was attending, the case could then be visited by the medical officer of health.

The parents of all school children should be made to understand that where there is any illness in the family notice of such illness should be sent to the sehool authorities whether the children are. kept at home or not, and whether the disease is supposed to be of an infectious nature or otherwise.

In addition to this visitation of suspects at home, there is the question of the examination of children actually attending school, and suspected by the teachers to be suffering from some infectious disease. I find that the present method of dealing with these is to send them home, and send the medical officer of health their names and addresses, so that he may visit and examine them at 
their homes. This method is very laborious and also slow. More frequently than not the symptoms observed by the teacher are not at all those of infectious disease, and the visit of the medical officer is simply time thrown away. The proper arrangement undoubtedly would be to have the children medically examined at the school. This might be done by the medical officer of health just as readily as visiting the home of the child, and would have the double advantage of letting him see any appearances which had been observed by the teacher, which might otherwise have vanished before he made his visit, and of allowing him to take action where necessary without any loss of time.

Inspection.-This leads me on to my second point-the school as an inspection ground. Inspection of children in schools for the purpose of detecting symptoms of infectious disease should be carried out regularly and systematically. It has been proposed that for this purpose, and for the object, I suppose, of examining generally into the health of the children, a medical officer should be appointed to each school or group of schools. It would clearly be impossible for the medical officer of health to make such systematic examinations. Now this would, no doubt, be the ideal system. I believe that in certain other countries-America, I think-such a system has been adopted; but failing such an arrangement, which, I fear, is not likely to be introduced here just yet, I consider that a daily examination should be made by every responsible teacher of the children under his or her care. Any child who presents symptoms of illness, as feverishness, which might be tested by the thermometer, headache, cough, ete., should be sent home at once. They should afterwards be visited by the attendance officer in order to ascertain the course of the illness, and not be allowed to return without a medical certificate either from the family doctor or the medical officer of health.

All teachers ought to be thoroughly well drilled in a knowledge of the early symptoms of the infectious diseases.

In addition to the examination of an individual as just mentioned, it may be necessary to examine a whole class or school in the attempt to discover if there is anyone in an infectious condition, and the cause of a number of known cases from this school. In my experience it is very rare to find such a one.

In conclusion, I must ask you to excuse me for putting before you facts which are no doubt already so familiar. My objects are to impress on you the utility and importance of sehool notification, and by means of discussion to come to some conclusion regarding the best method of carrying out the details of such a system. 